\title{
Characterizing the air pollution of the cities in the closure of corona virus disease 2019 in China
}

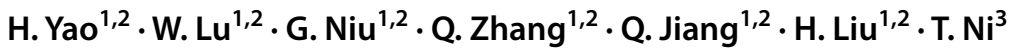

Received: 9 October 2020 / Revised: 8 February 2021 / Accepted: 6 April 2021 / Published online: 13 April 2021

(C) Islamic Azad University (IAU) 2021

\begin{abstract}
With the rapid development of industrialization and urbanization in China, energy and vehicle consumption have continued to increase in recent years and air pollution has become serious. In early 2020, Corona Virus Disease 2019 broke out in Wuhan, China. From January 29, 2020, several sources of the air pollution almost all stopped working, including gasoline burning vehicles, dust producing building sites, coal-fired factories, etc. Five indicators of the atmospheric environmental quality were observed from December 19, 2019 to April 30, 2020 in nine cities and 1-h average concentrations, 24-h average concentrations and Air Quality Index were assessed. The 1-h average concentrations of the nitrogen dioxide, the ozone and the sulfur dioxide showed obvious difference though the closure did not change the sequence of the five pollutants' concentrations in the air at diverse sampling moments. The changing of the 24-h average concentrations of the five pollutants indicated the amount of pollutants in the air were greatly affected by human activities. The nitrogen dioxide, the sulfur dioxide and the particulate matters decreased obviously in the closure. The air in the metropolis and the south-east cities were relatively clean and the pollutants' concentrations decreased slightly during the closure period. The northern and the heavy industrial cities showed significant drop on air pollution indicators and the air quality of the two city groups could be greatly improved if some effective measures could be taken of environmental management and regional development.
\end{abstract}

Keywords Corona virus disease 2019 · Air pollution · China

\section{Introduction}

Due to human activities, pollutants discharged into the atmosphere formed air pollution, which posed negative effect on human health and destroyed ecological balance (Liu et al. 2020; Chen et al. 2016; Li et al. 2016; West et al. 2016). The particulate matter pollution in the air has increased lung cancer's incidence, the sulfur oxides caused regional acid

Editorial responsibility: Samareh Mirkia.

H. Yao will handle the correspondence at all stages of refereeing and publication, also post-publication.

H. Yao

yaohong@ntu.edu.cn

1 School of Geography, Nantong University, Nantong 226019, China

2 Jiangsu Yangtze River Economic Belt Research Institute, Nantong 226019, China

3 School of Geographic and Oceanographic Science, Nanjing University, Nanjing 210023, China rain, the nitrogen oxides and ozone were the main pollutants causing photochemical smog (Jaffe and Zhang 2017; Jing et al. 2016; Liu et al. 2016; Wu et al. 2017). Besides, excessive ozone could also lead to the weakening of lung function and tissue damage (Jaffe and Zhang 2017; Jaffe et al. 2018; Tang et al. 2020; Yang et al. 2019).

With the rapid development of industrialization and urbanization in China, energy and vehicle consumption have continued to increase in recent years and air pollution has become serious (Gao et al. 2018; Song et al. 2017; Tian et al. 2018). The main sources of air pollution in China were the coal consumption for living and production and the main pollutants were particulate matters and sulfur dioxide (He et al. 2017; Hu et al. 2017, 2015; Jing et al. 2016). Particulate pollution, as a representative of air pollution, has become one of the major problems limiting the sustainable development of urban and regional economy and posing adverse effect on human health since 2000 and the average annual concentration of inhalable particulate matter exceeded the national second-class standard in two-thirds of cities in China (Song 
et al. 2017; Gao et al. 2018). With the popularity of the cars in Chinese families, the gasoline consumption has increased rapidly in recent years, and the pollution problems such as nitrogen dioxide and ozone have become increasingly noticeable. The sources of air pollution were complex and such man-made sources as industrial boilers and kilns, coal-fired power plants, industrial processes, dust, vehicle emissions, volatile sources, residents' living, agricultural sources were usually involved. The source analysis of the pollutants in the air has been one basic technology for the control of regional air pollution and it required the comprehensive application of multidisciplinary and multiple models (Cheng et al. 2016; Gao et al. 2018; Hu et al. 2017; Liu et al. 2020; Tian et al. 2018; Wu et al. 2017).

In early 2020, Corona Virus Disease-2019 (abbreviated as COVID-19) broke out in Wuhan, China. From January 29, 2020, all provinces in China have successively launched the first level emergency response mechanism for public health emergencies: most factories and construction sites were shut down, the residents stayed at home, the public transport in cities were stopped. This special period is called COVID-19 closure. In the COVID-19 closure, several sources of the air pollution almost all stopped working, including gasoline burning vehicles, dust producing building sites, coal-fired factories, etc. The COVID-19 in China was quickly and effectively controlled. From February 21st the residents' life and factories' production were slowly resumed and were gradually backed to the normal level by the end of March.

The period, from the end of 2019 to the closure in January, then gradually recovery from the end of February and returning to normal in April, was also the changing process of air pollution contributors. Thus the aims of the study were: (1) to observe the concentrations of air pollutants of the Cities in the four months in China, (2) to assess and characterize the air pollution in the COVID19 Closure, (3) to infer the contribution of various pollution sources to air pollution from the characterization in the period and analyze the impact of human activities on air pollution of the cities so that provide some information for decision makers on the control of regional air pollution in the nation.

Nine cities were selected as the observation sites and data were recorded from December 19, 2019 to April 30, 2020. The location of the cities was described in Fig. 1 and the characteristics were listed in Table 1.

Beijing, Shanghai and Guangzhou are three mega cities in China, with extremely high population density, economic density and traffic. Beijing is the capital of the nation, located in the north and east, being the political center, cultural center, scientific and technological innovation center of China. Shanghai is the international
Fig. 1 Sketch map of the nine observed cities

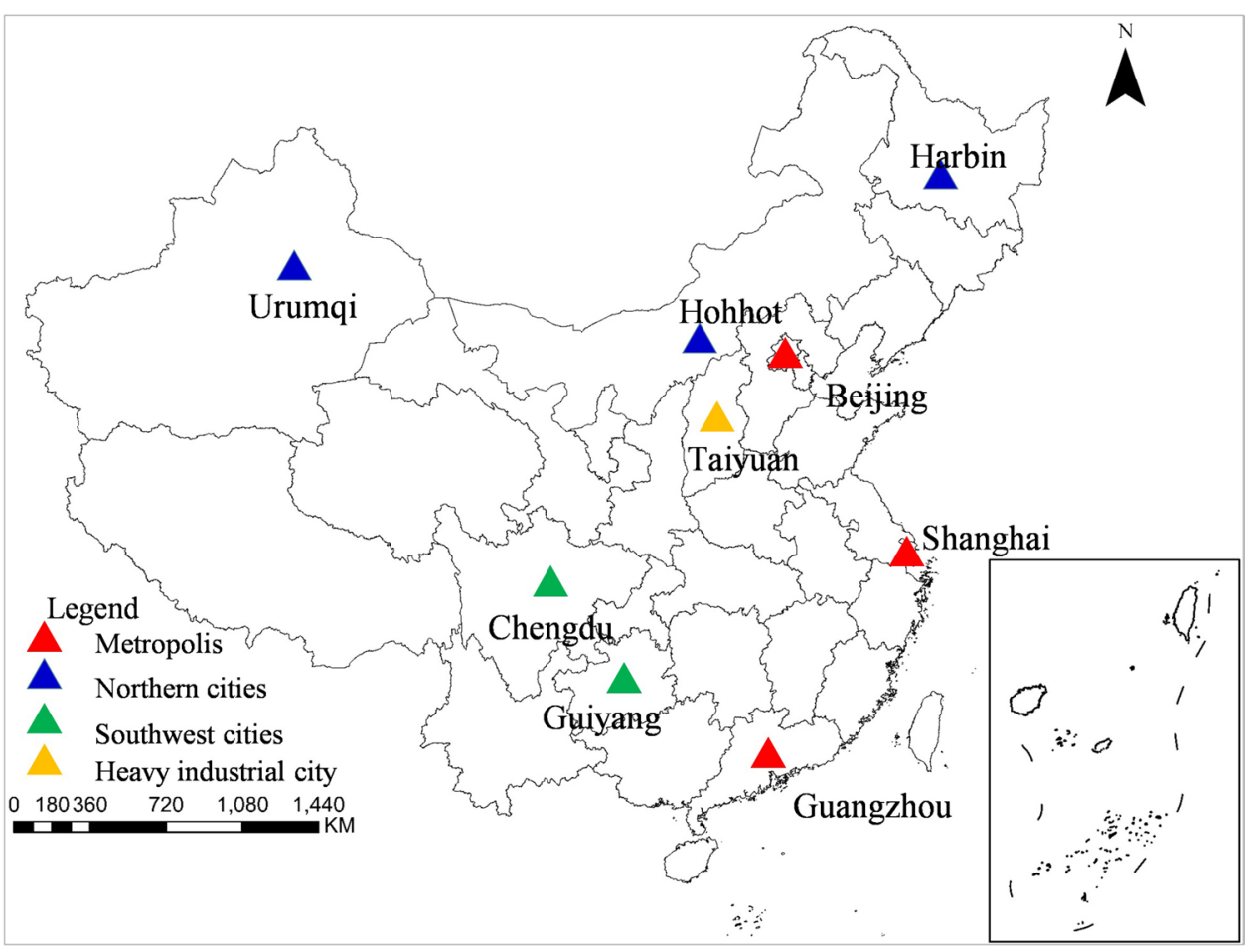


Table 1 Description of the observed nine cities*

\begin{tabular}{llllll}
\hline & Cities & H & P & Area & GDP \\
\hline Metropolis (MC) & Beijing & Y & 21.5 & 1485 & 3537 \\
& Shanghai & N & 24.4 & 1426 & 3815 \\
& Guangzhou & N & 15.3 & 1249 & 2362 \\
Typical southwest city (SC) & Guiyang & N & 4.8 & 360 & 404 \\
& Chendu & N & 16.6 & 949 & 1534 \\
Typical northern city (NC) & Urumqi & Y & 3.5 & 436 & 310 \\
& Hohhot & Y & 3.1 & 260 & 279 \\
& Harbin & Y & 10.8 & 435 & 630 \\
Typical heavy industrial city & Taiyuan & Y & 4.2 & 438 & 403 \\
(HC) & & & & & \\
\hline
\end{tabular}

* In table, H. means if central heating is provided in the city in winter, $\mathrm{Y}$ means yes and $\mathrm{N}$ is no. $\mathrm{P}$. denotes the number of population in 2019 and the unit is million. Area is the area of the city and the unit is square kilometers. GDP is the value of the gross domestic product of the city in 2019 and the unit is billion Yuan

economic, financial, trade, shipping and technological center in China. Guangzhou is in the east and south of the nation, being an important central city with international trade center and comprehensive transportation hub. The three cities were grouped as reprehensive metropolis in China (abbreviated as MC).

Chengdu and Guiyang are the capital cities of Sichuan Province and Guizhou Province, respectively. The two cities were both located in south-west China and the plateau and mountain are the main areas. The two cities have high green coverage and were both vital cities for ecological leisure resort. Chengdu and Guiyang were grouped as reprehensive south-west cities in China (abbreviated as SC).

Harbin, Hohhot and Urumqi are the provincial capital of Heilongjiang, Inner Mongolia Autonomous Region and Xinjiang Uygur Autonomous Region. The three cities are important central cities in northern China. The urban terrain in the north China is mainly plain with relatively small population and economic density. It is cold and dry in winter, and the coal consumption is large in winter due to centralized heating in these cities. The three cities were grouped as reprehensive northern cities (abbreviated as NC).

Taiyuan is the capital of Shanxi Province. It is one of the most important energy and heavy industry bases of the nation. Thus, the city is selected as the typical heavy industrial city (abbreviated as HC).

\section{Materials and methods}

\section{Data collection}

The five indicators of the atmospheric environmental quality, including the concentrations of the particulate matters with particle size below 10 microns (abbreviated as PM10) and those below 2.5 microns (abbreviated as PM2.5), nitrogen dioxide concentrations (abbreviated as NO2), sulfur dioxide concentrations (abbreviated as $\mathrm{SO} 2$ ) and ozone concentrations(abbreviated as $\mathrm{O} 3$ ) were observed from December 19, 2019 to April 30, 2020. All data were collected from the automatic monitoring stations of the atmospheric environment in the nine cities.

In the observation, the four periods, that was preclosure period (from December 19, 2019 to January 28, 2020), closure period (from January 28, 2020 to February 21, 2020), gradual resumption period (from February 22, 2020 to March 31, 2020) and post-closure period (the whole April), were covered and totally the observation lasted 134 days. Real-time concentrations of the pollutants were recorded every two hours from 6:00 a.m. to 10:00 p.m (nine intervals in total). The instantaneous concentrations at some time were not obtained for the data failing to be updated in real-time. The data collection rate was about $88 \%$ and finally 9556 groups of data were observed and applied in characterizing the air pollution of the cities in the COVID-19 closure in China.

\section{Characterization indicators}

Three indicators were applied in assessing the air quality of the cities: 1-hour average concentrations, 24-hour average concentrations and the value of the comprehensive air quality index (abbreviated as AQI).

\section{1-h average concentrations}

1-hour average concentrations, denoted as (1-hour-P) $)_{i j}$, were the arithmetic mean of the pollutants' concentrations in any hour. In the observation, the 1-hour average concentrations of the five pollutants were recorded in nine intervals per day in the nine cities. The indicators were evaluated by the average values of the nine cities at each moment using the following formula.

$(1-\text { hour }-\mathrm{P})_{i j}=\frac{\sum_{m=1}^{9}(1-\text { hour }-\mathrm{P})_{m i j}}{9}$ 

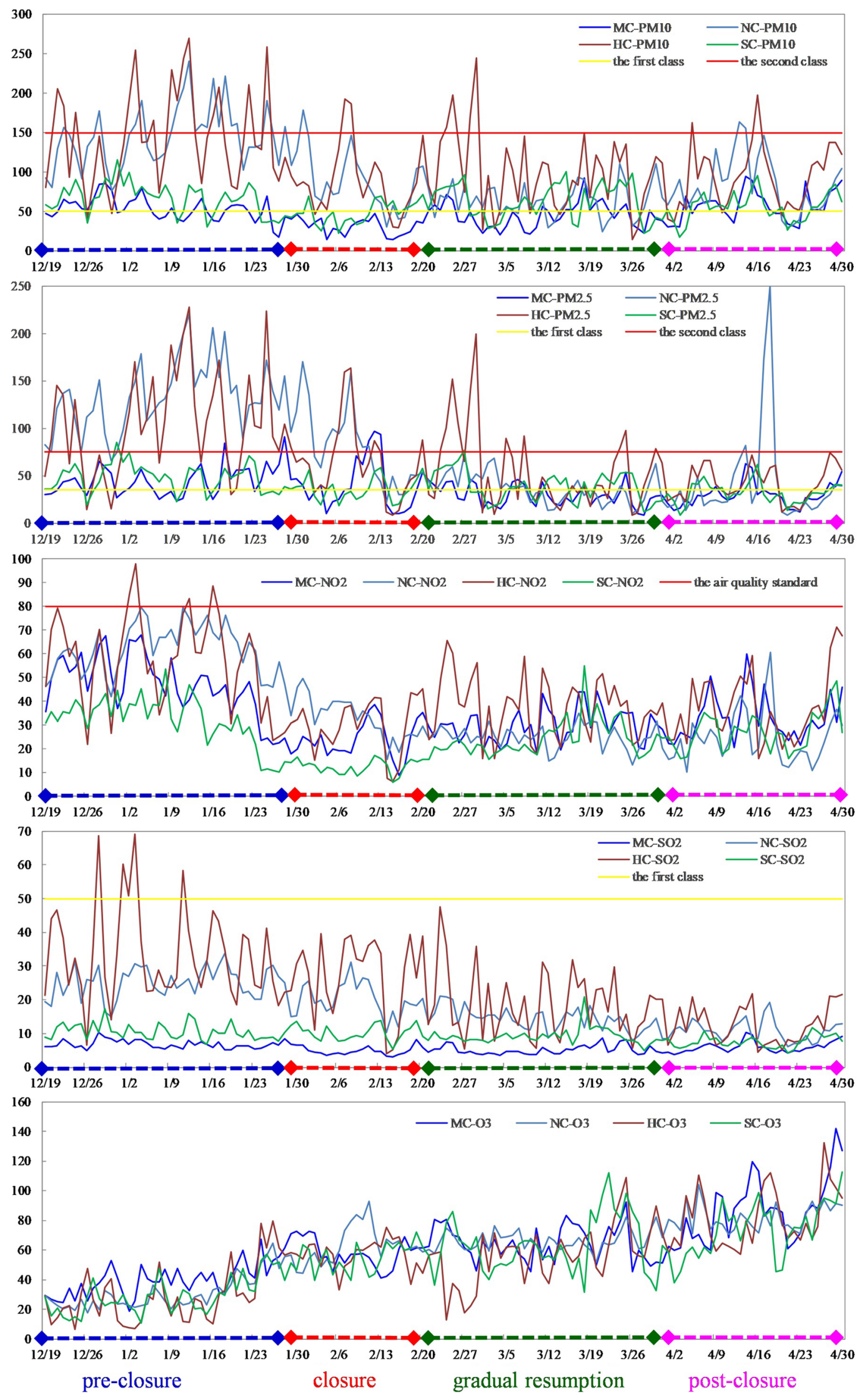
4Fig. 2 Distribution of 1-h average concentrations of the five pollutants. In figure, the abscissa is the observation time and the ordinate is the concentration of pollutants. All the units of the pollutants were $\mu \mathrm{g} / \mathrm{m}^{3}$. Four periods were identified on the abscissa with different colors of lines. The pre-closure period was from December 19, 2019 to January 28, 2020, the closure period was from January 29, 2020 to February 21, 2020, the gradual resumption period was from February 22, 2020 to March 31, 2020 and the whole April was the post-closure period

where (1-hour-P $)_{i j}$ was the 1-hour average concentration of the pollutant $\mathrm{P}$ on the $i$-th moment of the $j$-th day, for example (1-hour-NO2) meant 1-hour average concentration of the nitrogen dioxide in the air. (1-hour-P) $)_{m i j}$ was the 1-hour average concentration of the pollutant on the $i$-th moment of the $j$-th day in the $m$-th city. The units of the pollutants' concentrations were all $\mu \mathrm{g} / \mathrm{m}^{3}$.

\section{4-h average concentrations}

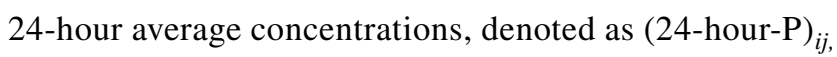
were the arithmetic mean of the pollutants' 24-hour average concentration in a natural day and it was actually the daily average concentrations. In the calculation, the cities were divided into four groups mentioned above. The indicators were assessed using the following formula.

$(24-\text { hour }-\mathrm{P})_{i j}=\frac{\sum_{m=1}^{9}(24-\text { hour }-\mathrm{P})_{m i j}}{9}$

where (24-hour-P) $)_{i j}$ was the 24-hour average concentration of the pollutant $\mathrm{P}$ on the $i$-th city group of the $j$-th day, for example (24-hour-SO2) meant 24-hour average concentration of the sulfur dioxide in the air. (24-hour-P) ${ }_{m i j}$ was the average concentration of the pollutant at the $m$-th moment in the $i$-th city group of the $j$-th day.

\section{AQI}

AQI was the most commonly used index in air quality evaluation in China and it was a comprehensive description of air quality status based on fine particulate matter, inhalable particulate matter, sulfur dioxide, nitrogen dioxide and ozone. The calculation procedure of the index referred to the Technical Regulations on Air Quality Index (AQI) (HJ633-2012) of China. 1-hour-AQI of the nine intervals from 6a.m. to 10p.m. and 24-hour-AQI of the four city groups were both analyzed in the study.

\section{Results and discussion}

\section{The 1-h average concentrations at the nine intervals}

The distributions of 1-hour average concentrations of the five pollutants at the nine intervals were described in Fig 2, in which the abscissa is the observation time and the ordinate is the concentration of pollutants. All the units of the pollutants were $\mu \mathrm{g} / \mathrm{m}^{3}$. Four periods were identified on the abscissa with different colors of lines. The pre-closure period was from December 19, 2019 to January 28, 2020, the closure period was from January 29, 2020 to February 21, 2020, the gradual resumption period was from February 22, 2020 to March 31, 2020 and the whole April was the post-closure period. In each figure, the 1-hour average concentrations of the corresponding pollutant at the nine intervals were listed.

Of the five pollutants, the 1-hour average concentrations of PM10 and PM2.5 had no regular temporal distribution, while the other three pollutants changed with time in a day. The concentrations of the nitrogen dioxide turned lower from 2:00p.m. to 6:00p.m and higher both from 8:00 a.m. to 10:00 a.m and from 8:00p.m. to 10:00p.m. The distribution of the 1-hour average concentrations of the ozone was opposite to those of the nitrogen dioxide, which gradually increased from 6 a.m., peaked at about 4-6 p.m., and then gradually decreased. The distributions were consistent with many research conclusions (Girgzdiene et al. 2002; Lu et al. 2010; Mao et al. 2003; Notario et al. 2012). The concentrations of the two pollutants fluctuated at diverse intervals. From the figure we can see that the concentrations of the ozone were mainly related to the light intensity and air temperature. When the concentrations of the ozone were low from night to morning, the concentrations of the nitrogen dioxide gradually increased, but when the concentrations of the ozone were high in the afternoon, the concentrations of the nitrogen dioxide decreased. Besides, the 1-hour average concentrations of the nitrogen dioxide were mainly affected by the flow of motor vehicles. The peak time of the commuting was 8:00-10:00a.m and 6:00-8:00p.m., and the concentrations of 1-hour-NO2 turned higher in the two intervals (Fig. 2). The distribution of 1-hour average concentrations of the sulfur dioxide was similar with that of the ozone, it increased from 6 a.m., peaked at about 12 a.m-2p.m., and then gradually decreased. 

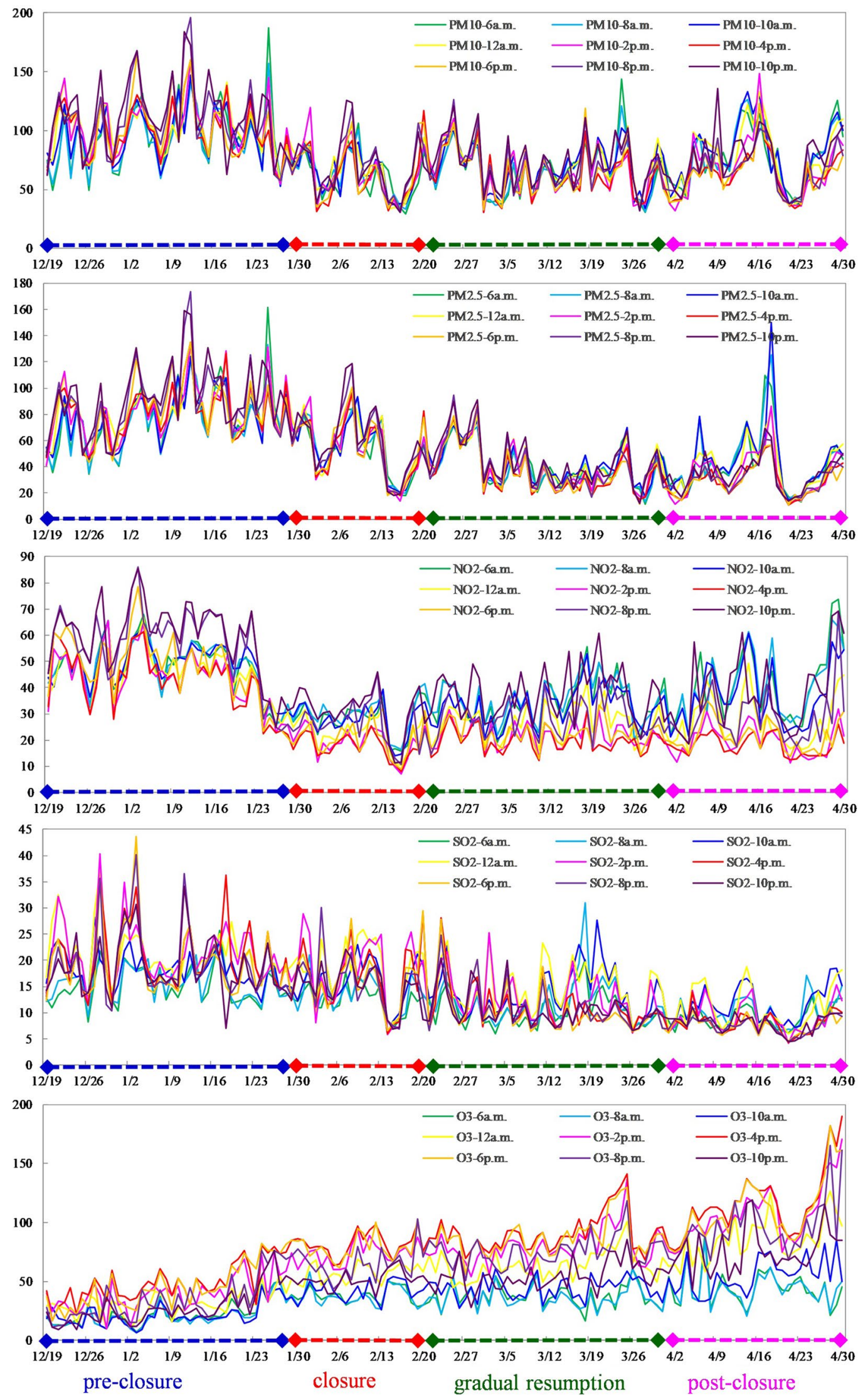
4 Fig. 3 Distribution of 24-h average concentrations in the four city groups. In figure, MC denoted Beijing, Shanghai and Guangdong, SC was Chengdu and Guiyang, NC was Harbin, Hohhot Urumqi and HC denoted Taiyuan. The Yellow straight line was the 24-h average concentration corresponding to the first grade air quality and the red one was that of the second grade

As figure shows, the distributions of 1-hour average concentrations of the five pollutants were consistent in the four periods from December 19, 2019 to April 30, 2020. The COVID-19 closure did not change the trend of the distribution of the pollutants in the air at diverse moments.

\section{The 24-h average concentrations in the four city groups}

The 24-hour average concentrations of the five pollutants in the four city groups were described in Figure 3. Of the nine cities, Beijing, Shanghai and Guangdong were grouped as reprehensive metropolis (abbreviated as MC), Chengdu and Guiyang were reprehensive south-west cities (abbreviated as SC), Harbin, Hohhot Urumqi were reprehensive northern cities (abbreviated as NC) and Taiyuan was regarded as the typical heavy industrial city (abbreviated as HC). In the figure, the abscissa is also the observation time and the ordinate is the concentration of pollutants. All the units of the pollutants were $\mu \mathrm{g} / \mathrm{m}^{3}$. Four periods were also identified on the abscissa with different colors of lines. The values of China's air quality standards on the pollutants were also shown on the figures. The Yellow straight line was the 24-hour average concentration of the pollutant corresponding to the first grade air quality (denoted as the first class in the figure) and the red one was that of the second grade (denoted as the second class). The standard values of the ozone and the second class of the sulfur dioxide were not applicable, and the standard values of the nitrogen dioxide in the two classes were the same.

The 24-hour average concentrations of the five pollutants showed significant differences in the four city groups and were greatly determined by human activities. The characteristics of the air pollution in the cities were mainly determined by the energy structure. Because $75 \%$ of the energy consumption in China was coal, the air pollution of the most cities was soot pollution. Among all cities Taiyuan was the most typical in China. The 24-hour average concentrations of the PM10, PM2.5, SO2 and NO2 of Taiyuan were all the highest among the four city groups, which was caused by the industrial structure and energy consumption of the city. The concentrations of the particulate matter and the sulfur dioxide in the metropolis were the lowest among the four city groups, which was due to the environmental protection and effective environmental management in these cities. The concentrations of the five pollutants in the south-west cities were maintained at a low level, which was related to their low economic density and favorable ecological environment.

The concentrations of the nitrogen dioxide, sulfur dioxide and PM2.5 decreased obviously in the COVID19 closure. The 24-hour-NO2 in February were only about half of those in January and December, 2019, and this trend was consistent in all the four city groups. The 24-hour-PM2.5 has been maintained at a low level from the COVID-19 closure till the end of April. The concentrations of PM10 decreased slightly in the COVID19 closure. The 24-hour-O3 continued to increase from December to April and the COVID-19 closure almost had no effect on the ozone concentrations. So from all the above we can infer that the amount of pollutants in the air were greatly affected by human activities, especially the nitrogen dioxide, the sulfur dioxide and the particulate matters.

\section{The characteristics of AQI}

The values of the 1-hour-AQI at the nine intervals and the 24-hour-AQI in the four city groups were described in Fig. 4. AQI has no units and the number ranged from 0 to 500. AQI values expressed different air quality levels and were significant guiding for the health protection and outdoor exercise intensity of different populations. The lower the index, the better the air quality is. According to the value of AQI, the air quality could be divided into from grade 1 to grade 6: excellent, good, mild pollution, moderate pollution, severe pollution and serious pollution. The AQI value of 0-50 indicated that the air quality was excellent. That of 51-100 denoted the air quality was good, it indicated that some pollutants may have a weak impact on the health of some sensitive people, who should reduce their outdoor activities. The AQI value of 101-150 indicated mild pollution; 151-200, moderate pollution; 201-300, severe pollution and $>300$, serious pollution. In the distribution of the 24-hour-AQI, different levels of air quality were distinguished by different colors of straight lines (Fig. 4).

The 1-h-AQI values at the nine intervals were randomly distributed, which indicated that the AQI values were influenced by many factors, such as instantaneous 

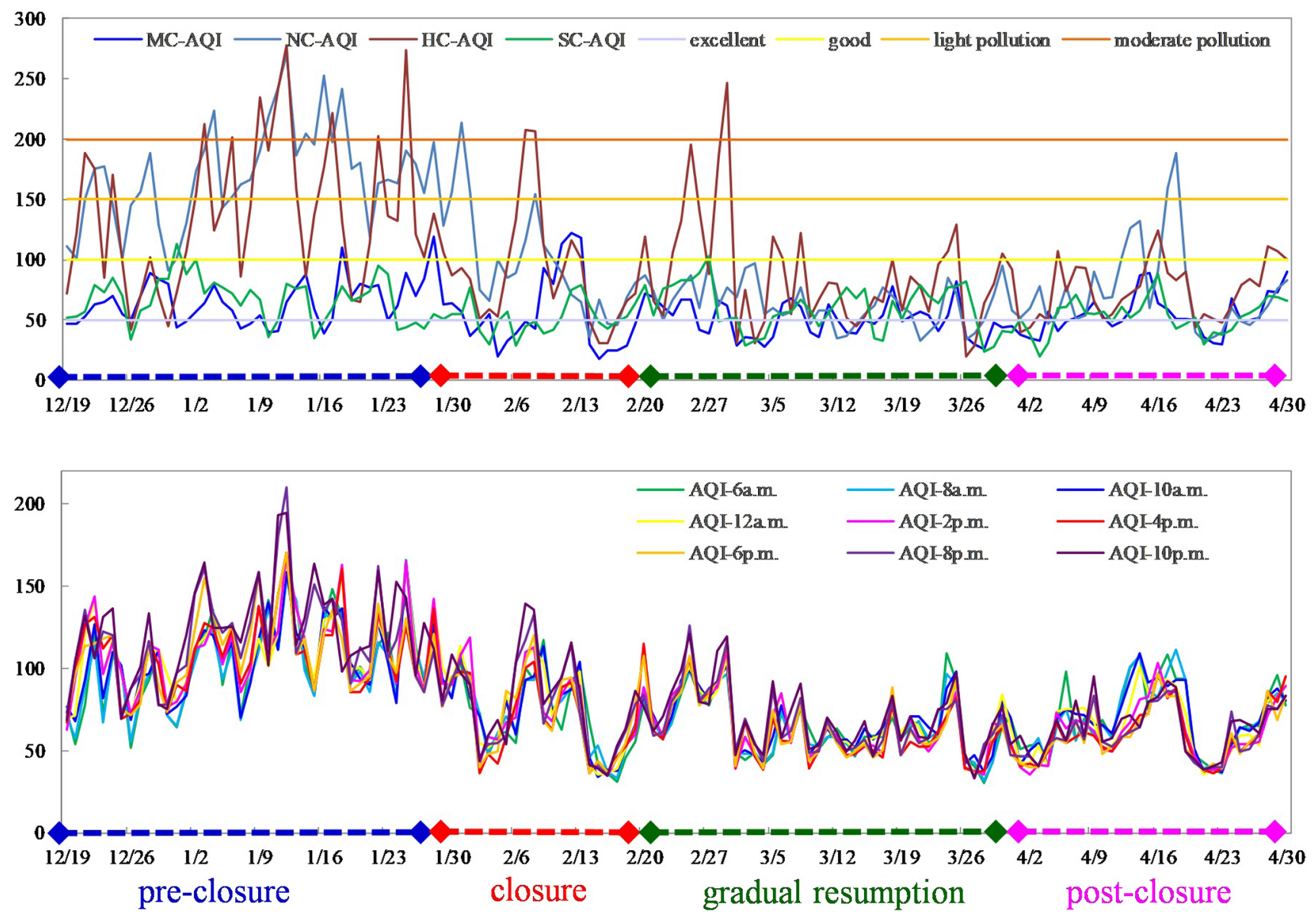

Fig. 4 Distribution of 1-h-AQI and 24-h-AQI

temperature, humidity, wind speed, wind direction, terrain and so on. In terms of the probability, the AQI values at $10 \mathrm{p} . \mathrm{m}$. were the most likely to be highest in a day and the AQI values from 12 a.m. to 2 p.m. were the most likely to have the lowest value of the whole day. This might be due to the sharp decrease in ground temperature in winter night, which led to the low temperature of the atmosphere close to the ground (Jeong and Park 2017; $\mathrm{Li}$ et al. 2017). The "temperature reversal" phenomenon occurred and made it difficult for pollutants to diffuse. As a result, the concentrations of the pollutants in the air at night could be higher than those during the day.

The AQI values of the MC and SC cities were mostly within 100 , indicating that the air in these two city groups were relatively clean. During the closure period, the 24-hAQI of the two groups decreased slightly. The AQI values of the $\mathrm{NC}$ and $\mathrm{HC}$ groups were rather high in the pre-closure period with both above 150 and sometimes even more than 200. After the COVID-19 closure, the AQI values dropped significantly and all being below 150 till the end of April. The temporal distributions of the AQI values showed that the air quality of the $\mathrm{NC}$ and $\mathrm{HC}$ city groups could be greatly improved if some effective measures could be taken on environmental management and regional development.

\section{Conclusion}

With the rapid development of industrialization and urbanization in China, energy and vehicle consumption have continued to increase in recent years and air pollution has become serious. In early 2020, Corona Virus Disease 2019 broke out in Wuhan, China. From January 29, 2020, several sources of the air pollution almost all stopped working, including gasoline burning vehicles, dust producing building sites, coal-fired factories, etc. Five indicators of the atmospheric environmental quality were observed from December 19, 2019 to April 30, 2020 in nine cities and totally 9556 groups of data were observed and applied in characterizing the air pollution of the cities in the COVID-19 closure in China. 
1-h average concentrations, 24-h average concentrations and Air Quality Index were assessed. The 1-h average concentrations of the nitrogen dioxide, the ozone and the sulfur dioxide showed obvious intervals' difference though the closure did not change the trend of the interval's distribution of the five pollutants in the air. The amount of pollutants in the air were greatly affected by human activities, especially the nitrogen dioxide, the sulfur dioxide and the particulate matters, which decreased obviously in the closure. The air in the metropolis and south-east cities were relatively clean and the pollutants' concentrations decreased slightly during the closure period. The northern and heavy industrial cities showed significant drop on air pollution indicators and the air quality of the two city groups could be greatly improved if some effective measures could be taken on environmental management and regional development.

Acknowledgements This work was sponsored by the National Natural Science Foundation of China (41501601). No conflict of interest exits in the submission of this manuscript, and the manuscript is approved by all authors for publication.

Authors contributions HY conceived and designed the study. WL, GN and QZ performed the assessment. WL, HY and GN wrote the paper. QZ, QJ, WL, HL and TN collected the data and critically reviewed the manuscript and added helpful explanations. All authors approved the final version of the manuscript.

\section{Declarations}

Conflict of interest The authors declare no conflict of interest.

Ethical approval This article does not contain any studies with human participants or animals performed by any of the authors.

\section{References}

Chen X, Zhang LW, Huang JJ, Song FJ, Zhang LP, Qian ZM, Trevathan E, Mao HJ, Han B, Vaughn M, Chen KX, Liu YM, Chen J, Zhao BX, Jiang GH, Gu Q, Bai ZP, Dong GH, Tang NJ (2016) Long-term exposure to urban air pollution and lung cancer mortality: A 12-year cohort study in Northern China. Sci Total Environ 571:855-861

Cheng YF, Zheng GJ, Wei C, Mu Q, Zheng B, Wang ZB, Gao M, Zhang Q, He KB, Carmichael G, Poschl U, Su H (2016) Reactive nitrogen chemistry in aerosol water as a source of sulfate during haze events in China. Sci Adv 2(12):e1601530

Gao JJ, Wang K, Wang Y, Liu SH, Zhu CY, Hao JM, Liu HJ, Hua SB, Tian HZ (2018) Temporal-spatial characteristics and source apportionment of PM2.5 as well as its associated chemical species in the Beijing-Tianjin-Hebei region of China. Environ Pollut 233:714-724

Girgzdiene R, Sopauskiene D, Girgzdys A (2002) The change in $\mathrm{O} 3, \mathrm{SO} 2$ and $\mathrm{NO} 2$ concentrations in Lithuania. Environ Sci Pollut Res Int 1:3-7
He JJ, Gong SL, Yu Y, Yu LJ, Wu L, Mao HJ, Song CB, Zhao SP, Liu HL, Li XY, Li RP (2017) Air pollution characteristics and their relation to meteorological conditions during 2014-2015 in major Chinese cities. Environ Pollut 223:484-496

Hu JL, Wu L, Zheng B, Zhang Q, He KB, Chang Q, Li XH, Yang FM, Ying Q, Zhang HL (2015) Source contributions and regional transport of primary particulate matter in China. Environ Pollut 207:31-42

Hu JL, Wang P, Ying Q, Zhang HL, Chen JJ, Ge XL, Li XH, Jiang JK, Wang SX, Zhang J, Zhao Y, Zhang YY (2017) Modeling biogenic and anthropogenic secondary organic aerosol in China. Atmos Chem Phys 17:77-92

Jaffe DA, Zhang L (2017) Meteorological anomalies lead to elevated O-3 in the western U. S. in June 2015. Geophys Res Lett 44:1990-1997

Jaffe DA, Cooper OR, Fiore AM, Henderson BH, Tonnesen GS, Russell AG, Henze DK, Langford AO, Lin MY, Moore T (2018) Scientific assessment of background ozone over the US: Implications for air quality management. Elementa-Sci Anthrop, p 6

Jeong JI, Park RJ (2017) Winter monsoon variability and its impact on aerosol concentrations in East Asia. Environ Pollut 221:285-292

Jing BY, Wu L, Mao HJ, Gong SN, He JJ, Zou C, Song GH, Li XY, Wu Z (2016) Development of a vehicle emission inventory with high temporal-spatial resolution based on NRT traffic data and its impact on air pollution in Beijing - Part 1: Development and evaluation of vehicle emission inventory. Atmos Chem Phys 16:3161-3170

Li SS, Williams G, Guo YM (2016) Health benefits from improved outdoor air quality and intervention in China. Environ Pollut 214:17-25

Li J, Du HY, Wang ZF, Sun YL, Yang WY, Li JJ, Tang X, Fu PQ (2017) Rapid formation of a severe regional winter haze episode over a mega-city cluster on the North China Plain. Environ Pollut 223:605-615

Liu F, Zhang Q, Ronald JV, Zheng B, Tong D, Yan L, Zheng YX, He KB (2016) Recent reduction in NOx emissions over China: synthesis of satellite observations and emission inventories. Environ Res Lett, $\mathrm{p} 1$

Liu B, Li Y, Wang L, Bi X, Dong H, Sun X, Xiao Z, Zhang Y, Feng Y (2020) Source directional apportionment of ambient PM2.5 in urban and industrial sites at a megacity in China. Atmos Res, p 235

Lu K, Zhang Y, Su H, Brauers T, Chou CC, Hofzumahaus A, C. Liu S, Kita K, Kondo Y, Shao M, Wahner A, Wang J, Wang $\mathrm{X}$, Zhu T (2010) Oxidant $(\mathrm{O}-3+\mathrm{NO} 2)$ production processes and formation regimes in Beijing. J Geophys Res Atmos, p 115

Mao HT, Wang WC, Liang XZ, Talbot RW (2003) Global and seasonal variations of $\mathrm{O}-3$ and $\mathrm{NO} 2$ photodissociation rate coefficients. J Geophys Res-Atmos, p 108

Notario A, Bravo I, Antonio Adame J, Diaz-de-Mera Y, Aranda A, Rodriguez A, Rodriguez D (2012) Analysis of NO, NO2, NOx, $\mathrm{O}-3$ and oxidant $(\mathrm{OX}=\mathrm{O}-3+\mathrm{NO} 2)$ levels measured in a metropolitan area in the southwest of Iberian Peninsula. Atmos Res 104:217-226

Song CB, Wu L, Xie YC, He JJ, Chen X, Wang T, Lin YC, Jin TS, Wang AX, Liu Y, Dai QL, Liu BS, Wang YN, Mao HJ (2017) Air pollution in China: Status and spatiotemporal variations. Environ Pollut 227:334-347

Tang X, Gao X, Li CL, Zhou QP, Ren C, Feng ZB (2020) Study on spatiotemporal distribution of airborne ozone pollution in subtropical region considering socioeconomic driving impacts: A case study in Guangzhou, China. Sustain Cities Soc, p 54 
Tian YZ, Liu JY, Han SQ, Shi XR, Shi GL, Xu H, Yu HF, Zhang YF, Feng YC, Russell AG (2018) Spatial, seasonal and diurnal patterns in physicochemical characteristics and sources of PM2.5 in both inland and coastal regions within a megacity in China. J Hazard Mater 342:139-149

West JJ, Cohen A, Dentener F, Brunekreef B, Zhu T, Armstrong B, Bell ML, Brauer M, Carmichael G, Costa DL, Dockery DW, Kleeman M, Krzyzanowski M, Kunzli N, Liousse C, Lung SCC, Martin RV, Poschl U, Pope CA, Roberts JM, Russell AG, Wiedinmyer C (2016) What we breathe impacts our health: improving understanding of the link between air pollution and health. Environ Sci Technol 50:4895-4904

Wu Y, Zhang SJ, Hao JM, Liu H, Wu XM, Hu JN, Walsh MP, Wallington TJ, Zhang KM, Stevanovic S (2017) On-road vehicle emissions and their control in China: a review and outlook. Sci Total Environ 574:332-349

Yang JB, Liu JL, Han SQ, Yao Q, Cai ZY (2019) Study of the meteorological influence on ozone in urban areas and their use in assessing ozone trends in all seasons from 2009 to 2015 in Tianjin, China. Meteorol Atmos Phys 131:1661-1675 